\title{
Response to inhaled histamine and 24 hour sodium excretion
}

\author{
P G J BURNEY, J R BRITTON, S CHINN, A E TATTERSFIELD, H S PLATT, \\ A O PAPACOSTA, M C KELSON
}

\begin{abstract}
A relation between the prevalence of asthma and economic development has been suggested by studies in migrants and other surveys in developing countries. That this correlation might be partially explained by an increased intake of salt in the diet is supported by the observation that sales of table salt in the different regions of England and Wales are independently correlated with mortality from asthma for men and for children. As part of a wider survey of asthma 138 men living in two Hampshire villages and aged 18-64 were given a bronchial histamine challenge test and had their 24 hour urinary excretion of sodium measured. Bronchial reactivity was strongly related to 24 hour excretion of sodium after allowing for the effects of age, atopy, and cigarette smoking, there being on average a 10 -fold difference in reactivity over the $95 \%$ range of sodium excretion recorded in the study.
\end{abstract}

The data suggest that a high sodium diet may potentiate bronchial reactivity.

\section{Introduction}

Pronounced differences in the prevalence of asthma have been noted in some developing countries, more affluent communities having the greater prevalence of the disease. ${ }^{14}$ The increased prevalence of asthma found among migrants to more affluent areas ${ }^{34}$

Department of Community Medicine, United Medical and Dental Schools of Guy's and St Thomas's Hospitals, St Thomas's Hospital, London SE1 7EH P G J BURNEY, MB, MFCM, senior lecturer in community medicine

S CHINN, MA, senior lecturer in medical statistics

A O PAPACOSTA, BSC, statistical assistant

M C KELSON, BA, research assistant

Respiratory Medicine Unit, University of Nottingham, City Hospital, Nottingham

J R BRITTON, MB, MRCP, research registrar

A E TATTERSFIELD, MD, FRCP, professor of respiratory medicine

Department of Chemical Pathology, Basingstoke General Hospital, Basingstoke, Hampshire

H S PLATT, BSC, MD, consultant clinical chemical pathologist

Correspondence to: Dr Burney. strongly suggests an environmental cause. The daily intake of sodium chloride is one factor which is known to rise with economic development. ${ }^{5}$ It is hard to test the hypothesis that the prevalence of asthma is related to salt intake in developing countries, where many other factors are also associated with economic development; however, within England and Wales age standardised regional mortality from asthma for youths and men (aged 15-64) and for children (aged 5-14) of both sexes has been shown to be significantly correlated with regional sales of table salt. ${ }^{6}$ Though the relations are strong and specific to mortality from asthma, correlations among groups of subjects may be spurious. ${ }^{7}$ Moreover, the previous analysis used purchases of table salt and mortality from asthma as proxies for sodium consumption and prevalence of the disease. We have therefore extended a cross sectional study of asthma in two villages in Hampshire to test the hypothesis that bronchial reactivity to histamine may be related to the 24 hour excretion of sodium.

\section{Subjects and methods}

A cross sectional survey of the prevalence of asthma was carried out in two villages and a market town in the south of England. ${ }^{8}$ A questionnaire designed to elicit symptoms of asthma and bronchial irritability, smoking history, and other personal information was distributed to all residents aged 18-64. A random $20 \%$ sample of those who replied and all those who stated that they had had "wheezing or whistling in the chest at any time in the last 12 months" were invited to attend for testing. Tests included histamine bronchial challenge and allergen skin tests.

Bronchial challenge tests were performed using the method and schedule of Yan et al..$^{9}$ Those who were breathless at rest, had a forced vital capacity of less than 1.5 litres, or had a forced expiratory volume in one second of less than $60 \%$ of forced vital capacity were not challenged. The remaining subjects were given increasing doses of histamine from a de Vilbiss No 40 handheld nebuliser, starting with $0.03 \mu \mathrm{mol}$ or $0.06 \mu \mathrm{mol}$ if they had good lung function and no symptoms of bronchial irritability. The test was stopped when the forced expiratory volume in one second had fallen below $20 \%$ of the control measurement, which was taken after an inhalation of physiological saline, or when $4 \mu \mathrm{mol}$ histamine had been given. The dose estimated to cause a fall of $20 \%$ in forced expiratory volume in one second $\left(\mathrm{PD}_{20}\right)$ was found by curve fitting which allowed extrapolation to $\mathrm{aPD}_{20}$ of up to $8 \mu \mathrm{mol}$ (Chinn $e t$ al, unpublished observations).

Skin tests were performed using prick tests and standard allergens (Bencard, Brentford, England) against cat fur, Dermatophagoides pteronyssinus, and mixed grass pollen in addition to saline and histamine controls. The mean diameter of the weal in two directions at $90^{\circ}$ to each other, one of which was the maximum diameter, was measured. The mean weal response to the three allergens was taken to represent the atopic state of the subject. 
All the men who came for bronchial challenge in the two villages were asked to collect a 24 hour urine specimen. They were allowed to do this on any convenient day. Written instructions were given to each man, who was asked to discard the first voided urine of the day and time the collection from that time to the final collection at the beginning of the next day. On completion the specimens were sent to the laboratory for measurements of volume and concentrations of sodium, potassium, and creatinine. The subjects were not told the hypothesis being tested.

Urinary electrolyte concentrations were measured on a Beckman Astra analyser using sodium and potassium ion selective electrodes, and creatinine was measured using a Jaffe rate reaction.

In order to control for the effects of other variables known to affect bronchial reactivity the response to histamine was regressed against the logarithm of the 24 hour excretion of sodium, potassium, and creatinine together with smoking habits of the subjects, their mean skin weal diameter, and their age. The latter terms in the model had been shown to be related to reactivity in an earlier study of a larger sample from the same survey. ${ }^{8}$ The regression of $\mathrm{PD}_{20}$ against the independent variables is, however, complicated because values of $\mathrm{PD}_{20}$ that are less than $0.03 \mu \mathrm{mol}$ (or $0.06 \mu \mathrm{mol}$ if this was the lowest dose given) or greater than $8 \mu \mathrm{mol}$ are unknown ("censored"). Three regressions are therefore presented, as discussed elsewhere. ${ }^{8}$ Firstly, the proportion of all men who had a $\mathrm{PD}_{20}$ of $8 \mu \mathrm{mol}$ or less was regressed against the independent variables using multiple logistic regression. Secondly, the $\log _{10} \mathrm{PD}_{20}$, for those in whom the $\mathrm{PD}_{20}$ value was known (between 0.03 and $8 \mu \mathrm{mol}$ ), was regressed against the same variables using multiple linear regression. These two regressions were carried out by using the program GLIM. ${ }^{10}$ Neither of these regressions uses all the information available on bronchial reactivity. A maximum likelihood estimate of the regression coefficients was therefore calculated using the method of Wolynetz. "This regression combines information on subjects using both censored and uncensored information on reactivity and thereby uses all the information available.

The independent variables used were the logarithms of the 24 hour excretion of urinary electrolytes after controlling for the three variables which had a significant association with the bronchial response to histamine in the larger random sample from the same survey. ${ }^{8}$ As urinary excretion of creatinine is related to both muscle mass and the completeness of the urine collection, however, height was added to the independent variables in the final multiple regression to control further for body size.

All the tests were carried out in March 1984, before the grass pollen season. Ethical permission was granted by the ethical committees of Southampton and Basingstoke. All subjects had the tests and likely side effects explained before challenge and gave written consent.

\section{Results}

Of the 216 men who came for lung function tests in the two villages, 205 had a histamine challenge test. Eleven were not tested because their initial lung function was too poor to allow histamine challenge or because they could not perform an adequate forced expiratory manoeuvre.

A total of 140 of the 205 men given histamine challenge tests produced urine samples. The volume of one sample was not recorded and so the specimen was excluded. A further specimen of $310 \mathrm{ml}$ with an estimated 24 hour creatinine excretion of $0.77 \mathrm{mmol}(0.09 \mathrm{~g})$ and a sodium excretion of $33 \mathrm{mmol}(\mathrm{mEq}) / 24$ hours was excluded as an outlier. All subjects in this part of the study had a $\mathrm{PD}_{20}$ (histamine) above $0.03 \mu \mathrm{mol}$ and 43 out of 138 were reactive to $8 \mu \mathrm{mol}$ of histamine or less. Table I shows the similarity in age, smoking history, mean skin weal diameter, and reactivity between those who did and did not give urine specimens. Table II gives the ranges and mean values for urinary volume and sodium, potassium, and creatinine concentrations. Before controlling for the other variables known to influence bronchial reactivity the geometric mean 24 hour sodium excretion was

TABLE I-Characteristics of men in two villages given bronchial challenge tests and of those who also gave urine specimens

\begin{tabular}{lcc}
\hline & $\begin{array}{c}\text { Histamine challenge and no } \\
\text { urine specimen } \\
(\mathrm{n}=67)\end{array}$ & $\begin{array}{c}\text { Histamine challenge and } \\
\text { urine specimen } \\
(\mathrm{n}=138)\end{array}$ \\
\hline Mean age (years) & $38 \cdot 1$ & $41 \cdot 5$ \\
No (\%) with PD ${ }_{20} \leqslant 8 \mu \mathrm{mol}$ & $14(21)$ & $43(31)$ \\
Smoking history: & $21(31)$ & $58(42)$ \\
No $\%$ never smoked & $18(27)$ & $37(27)$ \\
No (\%) ex-smokers & $28(42)$ & $43(31)$ \\
No (\%) current smokers & $1 \cdot 6$ & 1.9
\end{tabular}

$\mathrm{PD}_{20}=$ Provocative dose (of histamine) required to produce $20 \%$ fall in forced expiratory volume in one second.
TABLE II-Results of urine analysis in 138 men

\begin{tabular}{lccc}
\hline & $\begin{array}{c}\text { Range of } \\
\text { values }\end{array}$ & $\begin{array}{c}\text { Geometric } \\
\text { mean }\end{array}$ & $\begin{array}{c}95 \% \text { Range } \\
\text { assuming log normal } \\
\text { distribution }\end{array}$ \\
\hline 24 Hour volume $(\mathrm{ml})$ & $645-4653$ & 1678 & $762-2511$ \\
24 Hour sodium excretion $(\mathrm{mmol})$ & $58-459$ & 171 & $88-332$ \\
24 Hour potassium excretion $(\mathrm{mmol})$ & $27-140$ & 63 & $37-109$ \\
24 Hour creatinine excretion $(\mathrm{mmol})$ & $8 \cdot 5-78 \cdot 5$ & 18 & $8-42$
\end{tabular}

Conversion: $S I$ to traditional units-Sodium and potassium: $1 \mathrm{mmol}=1 \mathrm{mEq}$. Creatinine: $1 \mathrm{mmol} \approx 0 \cdot 1 \mathrm{~g}$.

TABLE III-Geometric mean sodium excretion in reactive and non-reactive men

\begin{tabular}{ccccc} 
Mean (SE) & $\begin{array}{c}\text { Geometric mean } \\
\text { Nog sodium } \\
\text { sodium excretion } \\
(\mathrm{mmol} / 24 \mathrm{~h})\end{array}$ & $\begin{array}{c}t_{136} \\
(\mathrm{p})\end{array}$ \\
\hline Nexcretion/24 h
\end{tabular}

\begin{tabular}{lllll}
\hline $\begin{array}{l}\text { Reactive } \\
\left(\mathrm{PD}_{20} \leqslant 8 \mu \mathrm{mol}\right)\end{array}$ & 43 & $2.258(0.019)$ & 181 & $1.44(0.10<\mathrm{p}<0.20)$ \\
$\begin{array}{c}\text { Unreactive } \\
\left(\mathrm{PD}_{20}>8 \mu \mathrm{mol}\right)\end{array}$ & 95 & $2.222(0.016)$ & 167 &
\end{tabular}

Sodium: $1 \mathrm{mmol}=1 \mathrm{mEq}$.

TABLE IV-Regression coefficients for multiple logistic regression of proportion of men with $P D_{20}$ (histamine) $\leqslant 8 \mu$ mol on skin sensitivity, age, smoking history, and urinary excretion of creatinine and electrolytes

\begin{tabular}{|c|c|c|c|c|}
\hline Factor & Estimate & SE & $\chi^{2}$ & df \\
\hline $\begin{array}{l}\text { Mean for } 18 \text { year old skin prick test negative } \\
\text { non-smoking subject with average excretion } \\
\text { of sodium potassium and creatinine }\end{array}$ & $-2 \cdot 161$ & & & \\
\hline Ex-smoker versus non-smoker & -1.516 & $\begin{array}{l}1.520 \\
1.520\end{array}$ & & \\
\hline Current smoker versus non-smoker & -0.6572 & 1.153 & & \\
\hline Age in: & & & & \\
\hline Non-smoker & -0.0126 & 0.0441 & $2 \cdot 2$ & 5 \\
\hline Ex-smoker & 0.0573 & 0.0490 & & \\
\hline Current smoker & 0.0666 & 0.0368 & & \\
\hline Skin sensitivity (mm weal) & $0 \cdot 4722$ & $0 \cdot 2566\}$ & & 2 \\
\hline$($ Age -18$) \times$ weal in $\mathrm{mm}$ & 0.0012 & $0.0104\}$ & $12 \cdot 05 \times$ & 2 \\
\hline Log sodium/24 h & $3 \cdot 168$ & 1.809 & $3 \cdot 3^{\star}$ & 1 \\
\hline Log potassium $/ 24 \mathrm{~h}$ & $-2 \cdot 692$ & $2 \cdot 250$ & $1 \cdot 5$ & 1 \\
\hline Log creatinine/24 h & -1.023 & $1 \cdot 245$ & $0 \cdot 7$ & 1 \\
\hline
\end{tabular}

${ }^{\star} \mathrm{p}<0 \cdot 10 .{ }^{\star \star \star} \mathrm{p}<0 \cdot 01$

slightly higher in the reactive $(181 \mathrm{mmol})$ than unreactive $(167 \mathrm{mmol})$ subjects, though not significantly so $(0 \cdot 10<\mathrm{p}<0 \cdot 20)$ (table III).

The logistic regression analysis of the proportion of the 138 subjects who had a $\mathrm{PD}_{20}$ less than $8 \mu \mathrm{mol}$ against smoking history, mean skin weal diameter, age, and urinary creatinine and electrolyte concentrations showed $\sum$ that the estimated regression coefficients were similar to those found in the earlier analysis of a larger random sample of 511 subjects from the same 3 . survey ${ }^{8}$ though in the present study no single factor was significant by itself $\delta$ (table IV). The relation with mean skin weal diameter taken together with its multiplicative interaction with age was significant $(p<0.01)$ and there was a 0 positive regression against log urinary sodium, which reached only the $10 \% \frac{}{3}$ level of significance. On including height also in the model the strength of $\mathrm{N}$ the relation between reactivity and log sodium excretion increased and $D$ became significant $(p<0.05)$, though the relation between reactivity and height was not itself significant $(p>0.05)$.

When the $43 \mathrm{PD}_{20}$ values between 0.03 and $8 \mu \mathrm{mol}$ were transformed to

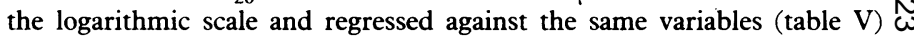
similar results were found and the coefficient with log urinary sodium was significant $(p<0.05)$. When both censored and uncensored information on 0

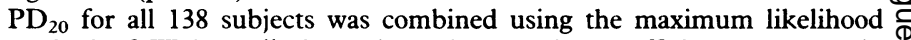
method of Wolynetz ${ }^{11}$ the estimated regression coefficients were again $\stackrel{\oplus}{\rightarrow}$ similar to those seen in the earlier analysis of data from the larger random sample for the variables common to both analyses, ${ }^{8}$ but in addition there was a significant relation between $\mathrm{PD}_{20}$ and sodium excretion (table VI). The $\overrightarrow{\mathbb{D}}$ coefficients that were significant in this study were for age in current smokers $\varrho$ $(p<0.05)$, mean skin weal diameter $(p<0.05)$, and the logarithm of the $\mathbb{D}$ 24 hour urinary excretion of sodium $(p<0 \cdot 05)$. There was a positive but non- $\bar{O}$ significant $(p>0.05)$ relation between $\log \mathrm{PD}_{20}$ and height. The relation 8 between $\log \mathrm{PD}_{20}$ and $\log$ sodium excretion was, however, strengthened by $\frac{0}{0}$ taking account of the height of the subjects, the regression coefficient decreasing from $-1.778(p<0.05)$ to $-1.924(p<0.02)$. 
The $95 \%$ range for sodium excretion lay between 90 and $330 \mathrm{mmol}(\mathrm{mEq}) /$ 24 hours (table II). Using the regression coefficients from table VI the expected $\mathrm{PD}_{20}$ was estimated to vary 10 -fold over this range. We looked to see whether the effect was stronger in any particular part of the sample. It appeared that the effect was more pronounced in the younger atopic subjects and in non-smokers, but the sample was too small to test these associations formally.

TABLE V-Regression coefficients for multiple linear regression of $\log _{10} P D_{20}$ values $\leqslant 8 \mu \mathrm{mol}$ against skin sensitivity, age, smoking history, and urinary excretion of creatinine and electrolytes

\begin{tabular}{|c|c|c|c|c|}
\hline Factor & Estimate & SE & $\mathrm{F}$ & df \\
\hline \multicolumn{5}{|l|}{$\begin{array}{l}\text { Mean for } 18 \text { year old skin prick test negative } \\
\text { non-smoking subject with average excretion }\end{array}$} \\
\hline Ex-smoker versus non-smoker & $\begin{array}{c}1 \cdot 013 \\
-0.2707\end{array}$ & $\begin{array}{l}0.4762 \\
0.5778\end{array}$ & \multirow{6}{*}{$1 \cdot 14$} & \multirow{6}{*}{5,32} \\
\hline Current smoker versus non-smoker & 0.2643 & 0.4457 & & \\
\hline Age in: & & & & \\
\hline Non-smoker & -0.0166 & 0.0177 & & \\
\hline Ex-smoker & -0.0156 & 0.0199 & & \\
\hline Current smoker & $-0.0339 \star$ & 0.0154 & & \\
\hline Skin sensitivity (mm weal) & $-0 \cdot 1390$ & $0.0917\}$ & 1.93 & 232 \\
\hline$($ Age -18$) \times$ weal in $\mathrm{mm}$ & 0.0033 & $0.0033\}$ & 1.93 & 2,32 \\
\hline Log sodium $/ 24 \mathrm{~h}$ & $-1 \cdot 6950^{\star}$ & 0.7670 & & \\
\hline $\log$ potassium $/ 24 \mathrm{~h}$ & 0.8724 & 0.8058 & & \\
\hline Log creatinine $/ 24 \mathrm{~h}$ & -0.7097 & $0 \cdot 4599$ & & \\
\hline
\end{tabular}

${ }^{\star} \mathrm{p}<0.05$
The reliability of a single 24 hour collection of urine is poor, ${ }^{13}$ but random error would tend to reduce the correlation with $\mathrm{PD}_{20}$ and is unlikely to produce a spurious correlation. If there was bias in the way that urine was collected, such that asthmatics collected more complete samples than non-asthmatics, a negative correlation between $\mathrm{PD}_{20}$ and 24 hour creatinine excretion would also be expected. The correlation with creatinine was, however, small, positive, and not significant. The exclusion of one person with a very low sodium output who was unreactive to histamine $\left(\mathrm{PD}_{20}>8 \mu \mathrm{mol}\right)$ does not alter the conclusion of the study, since inclusion would have strengthened the correlation between sodium output and bronchial reactivity.

Multiple regression, as used here, is the only method of analysis that can adequately control for the effects of other variables that influence the bronchial response to histamine. Because the data on reactivity were "censored" we have presented three regression analyses. The third of these (table VI) is the only one to make use of all the information available. All three regressions showed a strong relation between bronchial reactivity and a high sodium excretion after controlling for the confounding variables. In the logistic analysis (table IV) this did not reach conventional levels of significance $(0.05<\mathrm{p}<0 \cdot 10)$, though it was significant $(\mathrm{p}<0.05)$ after controlling for the height of the subjects. The lower level of significance may be attributed to the relative insensitivity of logistic analysis and the small size of the sample. Other relations that were

TABLE VI-Maximum likelihood estimates of regression coefficients for two models using both censored and uncensored data. Estimated $\log _{10} P D_{20}$ regressed on skin sensitivity, age, and smoking and for urinary electrolyte values where information available

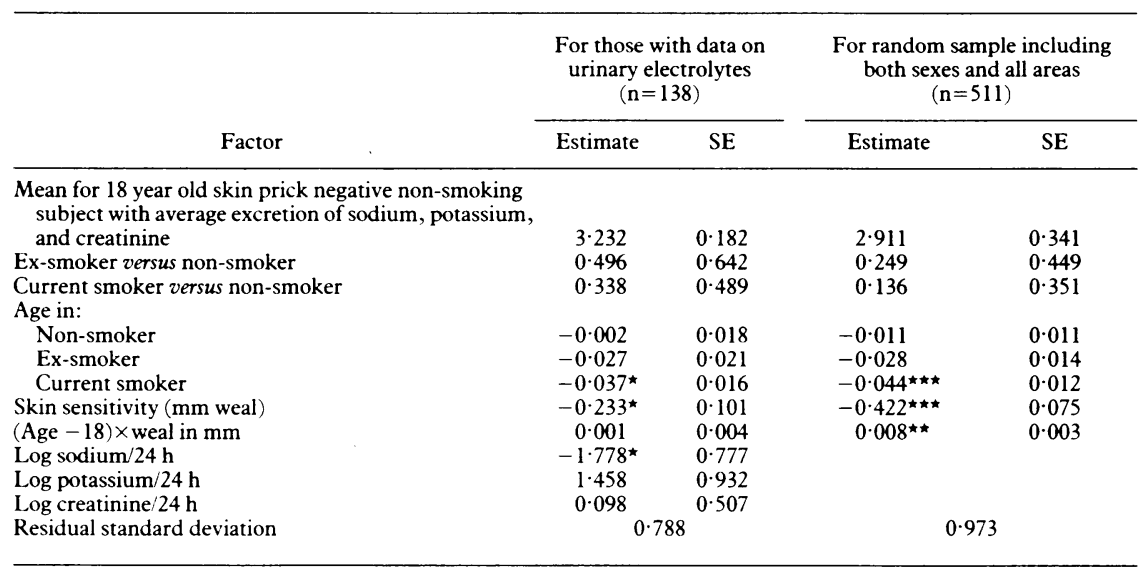

${ }^{\star} \mathrm{p}<0.05 .{ }^{\star \star} \mathrm{p}<0.01{ }^{\star \star \star \star} \mathrm{p}<0.001$.

\section{Discussion}

In a cross sectional survey of 138 men aged 18-64 living in two villages in Hampshire we have shown a strong and significant correlation between the response to inhaled histamine and the 24 hour excretion of sodium.

Histamine challenge tests are now accepted as a reliable measure of bronchial reactivity. The single determination $95 \%$ range in the survey of which this study formed a part was 1.63 doubling doses, as compared with 1.59 reported by Dehaut $e t a l^{12}$; if the data analysed were restricted to measurements obtained by the same person at the same time of day 24 hours later then the interval reduced to $1 \cdot 2$ doubling doses. The relation of bronchial reactivity to age, smoking, and skin sensitivity has already been shown in an analysis of 511 subjects randomly selected from those returning questionnaires in the same survey. ${ }^{8}$ In that analysis a statistically significant role was not found for other possible confounding factors, including smoking within the previous two hours, recent respiratory tract infections, social class, and recent medication. ${ }^{8}$ Of the 138 subjects studied here, 16 were taking selective $\beta_{2}$ agonists and 13 of these reacted to $8 \mu \mathrm{mol}$ histamine or less. Controlling for the use of these drugs strengthened but did not substantially alter the association between bronchial reactivity and sodium excretion. significant in the logistic analysis of the larger random sample were no longer significant in this smaller sample, though the regression coefficients were substantially unchanged.

We are unsure of the physiological mechanism underlying our observation, but recent studies on smooth muscle from guinea pigs and rabbits actively or passively sensitised in vitro and in vivo have shown hyper-reactivity and hyperpolarisation due to increased activity of the electrogenic sodium pump. ${ }^{14}$ This increased activity was subsequently shown to be due to an increased sodium influx which was inhibited by amiloride or tetrodotoxin. ${ }^{15}$ Possibly increased dietary sodium might potentiate such a mechanism, and this hypothesis is supported by the observation that the relation between sodium output and reactivity appeared to be more pronounced in the younger atopic men. Further work is required to establish whether the relation between sodium excretion and bronchial hyper-reactivity is dependent on the presence of atopy. In the mean time the physiological explanaton of our findings must remain speculative. We have considered whether the relation between bronchial response to histamine and dietary sodium is likely to be causal. The strength of the relation and its persistence after controlling for other factors known to influence reactivity suggests that this was the case, as does the consistency with the mortality data. On the other hand, no observational study can 
exclude the possibility that a confounding factor is responsible for the observed relation, and the lack of a well tested physiological explanation also dictates the need for caution.

The most likely confounding variable in this instance would be another dietary constituent. Several foods and food additives have been shown to produce immediate hypersensitivity reactions and diets high in sodium are likely to contain more food additives, as both additives and salt are found in comparatively large quantities in prepared food. We were not able to control for this possibility but studies suggest that asthma induced by food sensitivity is rare even among those with a history of food intolerance or with positive skin test reactions to food allergens. ${ }^{16}$ In our view such an explanation remains rather less likely than the straightforward acceptance of a direct cause and effect relation between sodium intake and bronchial reactivity.

We are grateful to Mr Frank Anderson and Mr Douglas Corfield for help with testing lung function, $\mathrm{Mr}$ David Chipchase for help with the analysis of urine samples, and Dr T E Roberts for helping to set up the study in the first instance. We also thank Dr R Lorge, Dr R Coppin, Dr D Pollard, and Dr N Norwell for allowing us to use their surgeries during this study, and $\mathrm{Mrs}$ Renee Witts who helped with the organisation. We are very grateful to the men in the two villages who agreed to collect 24 hour urine specimens with such good humour. We also thank Professor Walter Holland for his encouragement and help throughout the project and the Department of Health and Social Security for financial support.

\section{References}

1 Godfrey RC. Asthma and IgE levels in rural and urban communities in the Gambia. Clin Allerg 1975;5:201-7.

2 Anderson HR. Respiratory abnormalities in Papua New Guinea children: the effects of localitt and domestic wood smoke. Int I Epidemiol 1978;7:63-72.

3 Van Niekerk $\mathrm{CH}$, Weinberg EG, Shore SC, Heese $\mathrm{H}$ de V, van Schalkwyk DJ. Prevalence of asthma in $X$ hos Whingerg EG, Shore SC, Heese H de $V$, van asthma in Xhos

4 Waite DA, Eyles EF, Tonkin SL, O'Donnell TV. Asthma prevalence in Tokeluan children in two environments. Clin Allergy 1980;10:71-5.

5 Gleibermann L. Blood pressure and dietary salt in human populations. Ecology of Food and Nutrition 1973;2:143-56.

6 Burney PGJ. A diet rich in sodium may potentiate asthma: epidemiological evidence for a newT hypothesis. In: Holland WW, ed. Proceedings of Fogarty International Center workshop on etiologe of asthma, National Institutes of Health, 25-27 fune 1985

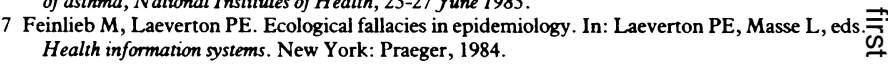

8 Burney PGJ, Britton JR, Chinn S, et al. The descriptive epidemiology of bronchial reactivity in añ adult population: results from a community study. Thorax (in press).

9 Yan K, Salome C, Woolcock AJ. Rapid method for measurement of bronchial responsiveness Thorax 1983;38:760-5.

10 Baker RJ, Nelder JA. The GLIM system, release 3. Oxford: Numerical Algorithms Group, 1978.

11 Wolynetz MS. AS139 Maximum likelihood estimation in a linear model from confined and censored normal data. Applied Statistics 1979;28:195-206.

12 censored normal data. Applied Statistics 1979;28:195-206. Dehau $P$, Rachiele A, Martin RR, Malo JL. Histamine dose response curves in asthma:

Liu Krod and high blood pressure: methodological problems. Am F Epidemiol 1979;110:219-26.

14 Souhrada $M$, Souhrada JF. Immunologically induced alterations of airway smooth muscle celc membrane. Science 1984;225:723-5.

15 Souhrada M, Souhrada JF. Sensitization-induced sodium influx in airway smooth muscle cells. 음

Am Rev Respir Dis 1985;131(No IV, p2):A356.
16 Bock SA, Buckley J, Holst A, May CD. Proper use of skin tests with food extracts in diagnosis ofin hypersensitivity to food in children. Clin Allergy 1977;7:375-83.

(Accepted 21 April 1986)

\section{YEARS AGO}

The system of obliging students to attend regulation courses of lectures on given subjects, is one which has been handed down to us by our forefathers, in matters educational, and is hallowed by its antiquity. It is probably a relic of the time when books were scarce, and oral instruction the best, and possibly the only means of obtaining information from those eminent men best qualified to give it, and whose ability with a pen did not always bear any proportion to their skill with the scalpel or the bleeding-bowl. Signs are not wanting at present to indicate that this system, venerable though it be, is destined to undergo serious modification, and, possibly, sooner or later, even to disappear. The reasons for the growing dissatisfaction are several. The lecturer may be a bad one. He may know what he is talking about, and be perfectly equal to carrying his ideas into execution, and yet be incomprehensible the moment he attempts to convey them by means of articulate speech. Or, on the other hand, the lecturer may be not only a scholar, and a ripe and good one, but able to convey his meaning concisely and intelligibly. Even then the result is scarcely better. While the wearied student seeks respite in slumber from the tediousness of the lecturer, who "is no orator as Brutus is," he may utterly fail to follow the facts and inferences of the abler man who condenses into one short hour the fruit of many hours, or it may be days, of labour. Those who have attended lectures on physiology during their first winter session, will readily appreciate this fact: the hopeless confusion of mind which supervenes after the first few sentences have been doled out, dealing with names and organs and functions, with which the aspirant physician or surgeon is intensely and pitiably unfamiliar, ultimately finds expression in a feeling of physical lassitude or indisposition to exertion, to which public attention may at length be called by an audible snore. Few people, probably, would venture to assert that they have derived much benefit from lectures on technical subjects, of which they knew very little beforehand. The major part of the lecture consists of matter which is contained in the text-books, and must, in any case, be assimilated therefrom; and the part which soars above that level is of necessity unintelligible to the student who follows, and does not precede, his lecturer. Such strictures, however, obviously do not apply to clinical lectures, which serve to call attention to the signs and symptoms which are the outward and visible manifestations of disease. This means of instruction is of the highest practical value, and should enable the student to make his own observations and deductions in a way that cannot be achieved by any other method. Nor do these remarks apply to lectures intended for senior students, or young newly fledged practitioners, anxious to fill up the gaps left after completion of the curriculum. The listener is, in this case, possessed of a sufficient basis of information to enable him to follow the arguments and endorse the deductions of the lecturer. Even here, though, there can be no doubt that an attentive perusal of the printed lecture is a much more efficient and economical means of deriving the benefit, than by a personal attendance in the lecture-room, where the mind may be unequal to the task of criticising and collating the views set before it. In foreign schools, attendance ap lectures is merely nominal, and no attempt is made to render it compulsory. The same latitude prevails in one of two London medical schools, and the examination results are not sensibly modified thereby. The time is certainly approaching when the student will claim to exercise his discretion as to the best means of employing his time, so far as lectures are concerned; and, if by judicious modifications in the standard of preliminary education required,, the age of the student for commencing his strictly medical studies be raised two or three years, the result would probably be found to be rather advantageous than otherwise. (British Medical fournal 1886;i:897.)

A short time since, a man, with a somewhat foreign appearance, presented himself at the house of a medical man, residing in the suburbs of London, and said that he had come to thank the doctor for kind attention and advice; received a couple of years previously. The latter experienced some difficulty? in calling the occurrence to mind, but felt reassured when the quondami patient explained how, since that time he had been abroad and, while in the tropics, it had occurred to him to invest in something which he might offer to his medical attendant, as a small token of his appreciation and gratitude. The medical man could not fail to be flattered at the expression of sentiments such as these. The visitor proceeded to explain that his investment had taken the form of a pair of grey parrots, which he now begged the medical man too accept. He added that the birds were not with him, but that if the medical. man would merely cover the carriage, he would immediately fetch themo from the Victoria Docks, where they were languishing. This was naturally atco once forthcoming, to the extent of half-a-crown, which our man pocketed;o and he soon after left on his errand. Whether some accident has befallen this unfortunate man, and incapacitated him from fulfilling his promise, orc whether he has lost the money for travelling expenses, is not clearly known. Certain it is that something, probably "circumstances over which he had no control," has prevented him from carrying out his project. There is a sort of sequel to this lamentable miscarriage of praiseworthy intentions. A few evenings after his visit, the medical man mentioned the incidents alluded to above, to a neighbouring practitioner, or rather, he had begun doing so, when the other, with a winning smile, suddenly exclaimed, "Is it parrots?"ס and then indulged in loud laughter. It transpired that, by a curious coincidence, he too had had a grateful patient animated by similar intentionso at about the same date; but, not being addicted to parrots, he had postponed payment of the carriage until their arrival, which has not yet taken place (British Medical Fournal 1886;ii:427.) 